\title{
ПАРЛАМЕНТСКИЙ КРИЗИС В ШВЕЦИИ
}

\begin{abstract}
Аннотация. Очередные парламентские выборы в Швеции прошли в начале сентября прошлого года, но до сих пор в стране не сформировано новое правительство. Между партиями идут постоянные переговоры о возможном сотрудничестве, создании коалиций, которые, однако, наталкиваются на взаимное неприятие политических требований. Рост популярности партии «Шведские демократы» означал усиление её влияния на оба политических блока, ни один из которых не имеет большинства голосов. Отношение к этой партии выявило противоречия внутри Альянса, который фактически оказался расколотым. Центристские партии в результате проголосовали против обоих кандидатов на пост премьер-министра: от Умеренной коалиционной партии (УКП) и от Сочиал-демократической рабочей партии (СДРПШ). Осталось две возможности голосования по кандидатуре премьер-министра. Если и они окончатся неудачей, страну ждут новые выборы.

Ключевые слова: парламентские выборы, политические партии Швеции, Социал-демократическая рабочая партия Швеции, Умеренная коаличионная партия, Шведские демократыл, партия Центра, коммунальные выборы, Альянс буржуазных партий, Красно-зелёнье.
\end{abstract}

\section{Затянувшийся выбор}

10 декабря 2018 г. в шведском парламенте в присутствии короля Швеции Карла XVI Юхана и кронпринцессы Сильвии состоялось торжественное заседание в честь столетия принятия закона о всеобщем равном избирательном праве, которое предопределило на годы вперёд демократическое развитие страны. Однако не всё благополучно сейчас в политической жизни страны - уже более четырёх месяцев, прошедших после выборов 9 сентября, страна живёт с переходным правительством в поисках ответа на вопрос, какая партия или межпартийная коалиция окажется в состоянии сформировать новое дееспособное правительство согласно волеизъявлению 87\% населения (один из самых высоких показателей избирательной активности в новейшей истории), пришедших на выборы. До сих пор никто в Швеции не знает, когда переходное правительство уступит власть новому, полностью легитимному кабинету. Всё чаще в прессе и в комментариях политиков можно заметить признаки нетерпения, разочарования, даже недоверия к существующей в стране парламентской системе. Политический обозреватель ведущей независимой газеты «Дагенс Нюхетер» Эва Стенберг ${ }^{1}$ прямо пишет о том, что терпению избирателей приходит конец, отмечая при этом уникальность нынешней ситуации, которая заключается в утере взаимопонимания между различными политическими партиями - основе политического компромисса, предопределявшего стабильность партийно-политической системы. В стране продолжается большой политический торг, в ко-

(C) Плевако Наталия Сергеевна - кандидат исторических наук, ведущий научный сотрудник, руководитель Центра Северной Европы ИЕ РАН. Адрес: 125009, Россия, Москва, ул. Моховая, д. 11, стр. 3. E-mail: natalia_plevako@mail.ru.

DOI: http://dx.doi.org/10.15211/vestnikieran620188

${ }^{1}$ Snart tar väljarnas tålamod med partierna slut. 10.12.2018 URL: https://www.dn.se/nyheter/politik/ewa-stenbergsnart-tar-valjarnas-talamod-med-partierna-slut/ (дата обращения:13.12.2018.). 
тором участвуют все восемь парламентских партий.

Ситуация с новым правительством так и не была решена к рождественским каникулам. Спикер парламента объявил 19 декабря, что следующее голосование по кандидатуре премьер-министра состоится 16 января 2019 г. после новогодних праздников, в течение которых партиям придётся продолжать искать новые варианты сотрудничества.

Политический пазл пока не складывается. Согласно конституции после четырёх безрезультатных голосований по кандидатуре премьер-министра назначаются внеочередные выборы в риксдаг. Два голосования уже прошли и не принесли успеха лидерам самых сильных партий: социал-демократу С. Лёвену и «умеренному коалиционеру» У. Кристерссону.

Это новое положение для страны, политическое устройство которой стабильно и, казалось, навсегда гарантирует быстрое и бесконфликтное формирование правительств не только большинства, но и, как это чаще случалось, меньшинства.

\section{Политические симпатии и разногласия}

Возникшая ситуация напрямую связана с приходом в политическую жизнь и стремительным укреплением позиций националистической партии Шведские демократы (ШД), которая в 2010 г. вошла в риксдаг и вскоре превратилась в силу, определяющую результаты парламентского соперничества двух практически равных по силам блоков. Увеличение мандатов этой партии в риксдаге позволяет им ставить условия обоим блокам, которые подчас выглядят как шантаж. Когда были объявлены результаты голосования на сентябрьских выборах, и стало ясно - силы «красно-зелёных» и Альянса почти равны ${ }^{1}$, руководство Шведских демократов заявило, что партия будет голосовать только за тот блок, который намерен с ней сотрудничать. Однако несмотря на отсутствие подобных гарантий, сразу после выборов националисты проголосовали вместе с правыми против кандидатуры на пост премьер-министра бывшего премьер-министра, социал-демократа С. Лёвена, хотя его блок набрал больше голосов, чем Альянс, а политика его кабинета обошлась без очевидных провалов. Дальнейшее развитие событий свидетельствует о том, что Шведские демократы отдают предпочтение буржуазным партиям, особенно Умеренной коалиционной и Христианско-демократической (ХДП). Это подтвердил опрос общественного мнения в ноябре 2018 г. Вопрос звучал так: какой партии, кроме своей, Вы больше всего симпатизируете? ${ }^{2}$ Голосующие за Шведских демократов, после своей партии поставили на второе место УКП (14,5\%) и на третье ХДП (8,7\%). Есть свидетельства об обратном процессе - среди сторонников ХДП 20,7\% симпатизируют ШД, а УКП - 41,4\% (только ХДП опережает ШД у голосующих за Умеренную коалиционную партию по числу симпатизирующих). Эти цифры свидетельствуют и о глубоких трещинах в Альянсе: правоцентристские партии - Центр и Либералы отказывались от какого-либо сотрудничества (даже неявного) со Шведскими демократами, а Умеренные и Христианские демократы, отрицая неизбежность зависимости Альянса от поддержки Шведских демократов, допускали создание двухпартийного правительства меньшинства. Раскол стал очевидным, когда спикер парламента после пяти недель зондирования почвы, которое должно было выявить возможности союзов для формирования правительства, объявил о том, что он ставит на парламентское голосование кандидатуру представителя «умеренных»У. Кристерссона на пост премьера. Тут же о своей непримиримой позиции заявила Либеральная

\footnotetext{
${ }^{1}$ 40,3 мандата у Альянса и 40,7 - у Красно-зелёных. У Шведских демократов - 17,5\%. Подробнее о результатах выборов см. статью Плевако Н.С. «Выборы в Швеции: Шведские демократы смешали карты». Научноаналитический Вестник ИЕ РАН 2018, №5. С.71.

2 URL: https://www.scb.se/contentassets/2bdd1d03007048c9a8f3338710bf91dd/me0201_2018m11_br_me60br1802. $\operatorname{pdf}$ (дата обращения: 23.12.2018).
}

Научно-аналитический вестник ИЕ РАН, 2018, №6 
партия, не пожелавшая отказаться от своих предвыборных обещаний не иметь ничего общего с партией Шведских демократов и не согласившаяся с «оппортунизмом» лидера УКП. Обе центристские партии предлагали в качестве союзника Альянса привлечь Партию окружающей среды, оторвав её от коалиции с социал-демократами, тем более что опыт парламентского сотрудничества с «зелёными» уже был. Однако У. Кристерссон отказался от такого предложения, считая, что это потребует длительных переговоров и увязок различных точек зрения партий по многим вопросам ${ }^{1}$. Фактически это был отказ от выдвигавшейся центристскими партиями идеи межблокового сотрудничества, где «зелёные» могли бы оказаться своего рода звеном, связующим блоки и не позволяющим Шведским демократам играть роль главного арбитра в парламентских спорах. Неделя перед голосованием в парламенте была напряжённой для партий Альянса: фактически рушился союз, созданный с большими трудностями и просуществовавший с 2004 г. Лидер партии Центра, молодая, энергичная А. Лёёф высказывала недовольство тем, что руководство УКП не предоставило ей возможность прозондировать почву для налаживания межблокового сотрудничества и спасения рушащегося Альянса. Не принесли успеха и уговоры руководителя ХДП Э. Б. Тур, обращённые к Либеральной партии, изменить свою точку зрения и поддержать кандидатуру У. Кристерссона на пост премьер-министра. Сам он предлагал формулу «1-2-3», т.е. создание правительства из одной, двух или трёх буржуазных партий, видимо, уже не надеясь собрать в нём полный партийный состав. Накануне парламентского голосования стало ясно, что центристские партии не поддержат кандидатуру У. Кристерссона. Так и произошло: он не смог собрать большинства голосов в риксдаге.

Начался новый тур переговоров: теперь предстояло голосование за кандидатуру социал-демократа С. Лёвена, перед которым также открылась призрачная возможность найти варианты многопартийного парламентского сотрудничества. Логика предыдущего голосования подсказывала, что потенциальными союзниками социал-демократов могли стать либералы и центристы, которые были за налаживание межблокового сотрудничества. Поэтому все усилия были направлены на поиск возможных компромиссов между ними. Обе центристские партии выставили С. Лёвену ряд требований, и в случае их принятия он мог рассчитывать на поддержку при вотировании своей кандидатуры. Прошедшие переговоры не были лёгкими, ибо ряд требований в сфере социальной политики шёл вразрез с принципами социал-демократов и Центрального объединения профсоюзов Швеции.

Наиболее значимыми были разногласия в области трудовых отношений, базовых для функционирования шведской модели, полного крушения которой не хотели допустить социал-демократы. Именно по этим вопросам ощущалось наибольшее давление на партию со стороны профсоюзов. Одним из принципов трудовых отношений как важнейшей составляющей шведской модели являются прямые переговоры между профсоюзами и предпринимателями, на которых решаются основные вопросы производственной жизни. И профсоюзы и работодатели изначально не хотели, чтобы их взаимоотношения регулировались законодательными актами, которые могли бы стать «прокрустовым ложем» для живого переговорного процес$\mathrm{ca}^{2}$. В условиях ослабления влияния профсоюзов на производственную жизнь, наметившегося с последнего десятилетия XX в., правые партии вновь выступают с инициативой для законо-

\footnotetext{
1 Kris i Alliansen: partiledarna i öppna bråk. 06.11.2018. URL: https://www.dn.se/arkiv/nyheter/kris-i-alliansenpartiledarna-i-oppna-brak/ (дата обращения: 25.12.2018).

2 Основы трудовых отношений были заложены так называемым Сальтшёбаденским соглашением, заключённым в 1938 г. Его принципов придерживались участники рынка труда. В конце 1970-х гг., в рамках политики экономической демократии шло активное обсуждение законодательного закрепления некоторых пунктов трудового права, однако профсоюзы активно сопротивлялись этому, оставив действенным переговорный процесс.
} Научно-аналитический вестник ИЕ РАН, 2018, №6 
дательного решения многих проблем рынка труда. Так, центристские партии выставили С. Лёвену требование, что более низкая оплата труда (70\%) при поступлении на работу иммигрантов должна регламентироваться законом. При этом даже предприниматели, не заключившие коллективный договор с профсоюзом, имеют право на такую оплату. Социал-демократы, напротив, считают, что этот вопрос должен решаться на переговорах между профсоюзами и предпринимателем, а государство должно выделять средства, чтобы работа дополнялась возможностью получения образования ${ }^{1}$. СДРПШ выступает против частной инициативы в сфере компетенции биржи труда, деятельность которой контролирует государство. Разногласия касаются и механизмов увольнения. Буржуазные партии считают, что не стаж работы, а компетентность работника должны быть определяющими, когда предприниматель решает, кто должен быть уволен. При этом партия Центра настаивает, что подобный принцип должен распространяться на все предприятия с числом работников более 50 человек. Партия Центра предложила создать комиссию по вопросам рынка труда, в которой должны быть рассмотрены эти предложения.

Длительные переговоры между центристскими партиями и СДРПШ не принесли ожидаемого результата. Накануне голосования по кандидатуре С. Лёвена в риксдаге и центристы и либералы заявили, что не проголосуют за его кандидатуру, так как их требования не были приняты. Таким образом, и второе голосование 14 декабря в парламенте окончилось безрезультатно. Центристские партии, недостаточно сильные, чтобы претендовать на главную роль в формировании кабинета, однако, фактически стали определять судьбу будущего правительства. За их голоса безуспешно боролись оба блока. Либералы затягивали переговорный процесс, а руководитель партии Центра была непримирима на всех стадиях переговоров, за что снискала в журналистских и политических кругах имя «Госпожа Нет». Но вот 21 декабря С. Лёвен заявил о том, что допускает возможность компромисса с партией Центра по трудовому праву для того, чтобы создать коалиционное правительство. Это заявление было позитивно оценено А. Лёёф, которая не исключила мысль о возможном сотрудничестве с Красно-зелёным блоком.

Но опасения по поводу возможного компромисса социал-демократов и центристских партий, и как следствие изменение в сфере трудовых отношений высказало Центральное объединение профсоюзов Швеции в лице своего председателя К.-П. Торвальдссона. В интервью Бюро новостей Швеции он заявил, что ЦОПШ относится критически к возможному компромиссу СДРПШ и партии Центра, условием которого с введением законодательного принципа фактически является нарушение традиционного для страны трудового права. Он отметил, что предпочтительнее в таком случае были бы внеочередные выборы в парламент, но не подобный компромисс ${ }^{2}$. Перед лицом значительных разногласий, таким образом, может оказаться союз социал-демократов с профсоюзами, что привело бы к нежелательным последствиям для политической жизни Швеции.

Раскол во мнениях о возможном сотрудничестве и партийных идеологических ценностях характерен и для Умеренной коалиционной партии. Неоднозначная позиция руководства по вопросу о сотрудничестве со Шведскими демократами, фактический уход центристских партий в оппозицию к УКП создаёт почву для поиска на местах возможных вариантов со-

\footnotetext{
${ }^{1}$ Stridsfrågorna där partierna måste komma överens 30.11.2018. URL: https://www.google.com/url?sa=i\&source= images\&cd=\&ved=2ahUKEwjdqrOZ-djfAhVmqYsKHUCnAi8QjRx6BAgBEAU\&url=https\%3A\%2F\%2Fwww.dn.se \%2Fnyheter\%2Fpolitik\%2Fstridsfragorna-dar-partierna-maste-komma-overens\%2F\&psig=AovVaw14yJ9Hc4FTO5d7 8v3CxH5D\&ust=1546856912543630 (дата обращения: 20.12.2018).

${ }^{2}$ LO:Hellre extraval än förändrad arbetsrätt.21.12.2018. URL: https://www.dn.se/nyheter/politik/lo-hellre-extraval-anforandrad-arbetsratt/ (дата обращения: 26.12.2018).
} 
трудничества с различными политическими силами в вопросах коммунального управления. В некоторых коммунах «умеренные» входят в соглашение со Шведскими демократами, в Стокгольме оформился союз четырёх партий Альянса с партией Окружающей среды. «Дагенс Нюхетер» указывает на признаки возникающего кризиса фундаментальных ценностей в политической партии. «В действительности представители местной власти не обращают внимания ни на партийное руководство, ни на руководящие принципы партии» ${ }^{1}$.

Спикер риксдага, который не дождался никаких результатов от лидеров партий, продолжает вести переговоры с претендентами на пост премьер-министра.

\section{Изменения в симпатиях избирательного корпуса}

Безрезультатные поиски союзников по коалиции, бесконечные переговоры и невозможность в течение длительного времени сформировать правительство отразилось на настроениях избирательного корпуса. В декабре был проведён очередной опрос общественного мнения, который выявил довольно значительные подвижки в симпатиях избирателей по отношению к существующим политическим блокам и отдельным партиям. Самые значительные потери понесла партия Центра, отказавшаяся поддерживать и тот и другой блок. Очевидно, терпению избирателей приходит конец, и они не воспринимают политику руководства партии как принципиальную идеологическую позицию. Согласно последним опросам процент поддержки партии Центра снизился с 10\% в сентябре до 7\% в декабре. Это самый низкий показатель с мая 2016 г. Меньше голосов потеряли Либералы (соответственно 5 и 4\%). Усилилась партия христианских демократов, которой перед выборами предрекали уход из риксдага (с 5 до 7\%). По всей видимости, повлияла чёткая позиция её руководства на формирование правительства. У «умеренных»- результат сохранился. Самый значительный прирост симпатизирующих - у социал-демократов (с 28 до 32\%). Это лучший с января 2015 г. результат. Союзники СДРПШ по блоку остались с неизменными показателями. Симпатии к Шведским демократам выросли (с 18 до 20\%). Число симпатизирующих обоим блокам изменилось: краснозелёный блок, по опросам, имеет 44\% (в сентябре 40,7\%), Альянс - 37\% (в сентябре 40,2\%)

Все понимают, что опросы вещь ненадёжная. Поэтому идея новых выборов, связанных, кстати, с огромными расходами, что само по себе не может нравиться шведам, многим кажется сомнительной и рискованной. Хорошие, при этом не гарантирующие реального усиления позиций в политической жизни перспективы, у СДРПШ и Шведских демократов. Но у первых ничего не получится без союзов с другими политическими силами. А это значит новое погружение в неопределённость переговорного процесса без очевидной перспективы успеха. У вторых сейчас нет шансов найти прочного и надёжного партнёра. Остальным партиям новые выборы мало что прибавят, а некоторым из них (в первую очередь либералам, а также Христианским демократам и даже партии Центра очень есть, чем рисковать). Все это понимают. И остаются важнейшие проблемы сегодняшней Швеции: выработка эффективной иммиграционной политики взамен не принесшего успеха курса на мультикультурализм, разрешение сомнений по поводу судьбы шведского нейтралитета, возвращение к некогда высоким темпам экономического роста, финансирование социальной политики. Какие политические силы будут определять дальнейшее развитие страны, будет ли найден компромисс в правительственном вопросе - пока остаётся неясным.

\footnotetext{
${ }^{1}$ Kristerssons ekvation är omöjlig att knacka. 29.12.2018 URL: https://www.dn.se/ledare/kristerssons-ekvation-aromojlig-att-knacka/ (дата обращения 30.12.2018).

2 DN/Ipsos: Stort tapp för Centerpartiet.19.12.2018. https://www.dn.se/nyheter/politik/dnipsos-stort-tapp-for-center partiet/URL: https://www.dn.se/nyheter/politik/dnipsos-stort-tapp-for-centerpartiet/ (дата обращения 24.12.2018).
}

Научно-аналитический вестник ИЕ РАН, 2018, №6 


\section{Список литературы}

Н.С. Плевако. Швеция: реформизм против реформы?: к проблеме «экономической демократии» в 1960-80-е гг. - М.: Наука. 1990. 109с.

\section{References}

Plevako N Natalia. Sweden: Reformism Contra Reform? To the Problem of «economic democracy 1960-80». Moscow. 1990.

Dagens Nyheter https://www.dn.se.

Svenska Dagbladet https://www.svd.se.

Aftonbladet https://www.aftonbladet.se.

Statistiska Centralbyrå https://www.scb.se.

\section{Parliament Crisis in Sweden}

Author. Plevako Natalia, Candidate of Sciences (History), Head of the Centre for Northern Europe Studies, Institute of Europe, Russian Academy of Sciences. Address: 11-3, Mokhovaya str., Moscow, Russia, 125009. E-mail: natalia_plevako@mail.ru.

Abstract. The parliamentary elections in Sweden were held September 9 last year, but the country has not formed a new government yet. Between the parties constant negotiations on possible cooperation, the creation of coalitions are carrying on, which, however, encounter mutual rejection of political demands. Strengthening the Swedish Democrats party meant increasing of its influence on both political blocs, neither of which has a majority vote. The attitude towards this party revealed contradictions within the Alliance, which actually turned out to be split. As a result, the centrist parties voted against both candidates for the post of Prime Minister (from the Moderate coalition party and the Social Democrats). There are only two opportunities to vote on the Prime Minister's candidacy. If they fail, the country will face new elections.

Key words: parliamentary elections, political parties of Sweden, Swedish Social democratic Party, Moderate Coalition Party, Swedish Democrats, Center party, nationalism, populism, communal elections, Alliance of bourgeois parties, Red-green bloc.

DOI: http://dx.doi.org/10.15211/vestnikieran620188 